\title{
Identidades em construção
}

\author{
Maria Silvia Casagrande Beozzo Bassanezi*
}

TRUZZI, O. Italianidade no interior paulista. Percursos e descaminhos de uma identidade étnica (1880-1950). São

Paulo: Editora Unesp, 2016.

0 que acontece quando culturas diferentes se encontram? Essa pergunta-chave do campo da História mundial encontra boas respostas nos estudos migratórios, com suas pesquisas sobre deslocamentos populacionais específicos e contatos compartilhados, trocas e interações entre diferentes povos que acabam por dividir o mesmo espaço em épocas determinadas da história.

De forma geral, o contato entre duas sociedades abre possibilidades para a inovação e a remodelação das identidades originais, mas também envolve tensão e conflito. Como diz o historiador Peter Stern (2007, p. 18-19), “Poucas sociedades se convertem rápida ou totalmente para os padrões da outra, mesmo quando existem contatos intensos [...] o que ocorre com mais frequência é um conjunto de compromissos". No caso dos imigrantes, os hábitos, as crenças, os valores trazidos se misturam com os elementos da cultura no local de chegada. Dessa forma, em um contexto de culturas em contato, as identidades étnicas também mudam ao longo da experiência migratória, em um processo social complexo que passa por momentos e intensidades diferentes, envolvendo permanências e rupturas, em que o confronto com o "outro" e as circunstâncias vivenciadas são importantes para definir o "nós".

Nas décadas finais do século XIX e nas primeiras do século XX, o interior paulista, assim como a capital, se constituiu num local de confluência de imigrantes de diferentes etnias, dos quais os italianos foram os mais volumosos. Nesse caso, contudo, a questão da identificação étnica era ainda mais complexa: procedentes de uma Itália recém-unificada, marcada por diferenças regionais intensas, vênetos, trentinos, calabreses, friulanos, lombardos, puglianos, sicilianos e outros passaram a ser vistos e se viram como "italianos"

\footnotetext{
*Núcleo de Estudos de População “Elza Berquó” (Nepo), Universidade Estadual de Campinas (Unicamp), Campinas-SP, Brasil (msilvia@nepo.unicamp.br).
} 
em terras brasileiras. Isso se deu em razão de sua condição de imigrante em contato com a cultura local, em que o "outro" (também!) eram muitos (nativos, ex-escravos, outros imigrantes estrangeiros). De fato, as circunstâncias vivenciadas foram importantes para definir o "nós" - a identidade étnica italiana, ou italianidade - e a inserção dos elementos identificados como tal na sociedade paulista.

Esse processo de extrema relevância para a história do Brasil (e dos brasileiros) ainda não foi analisado em toda sua extensão, principalmente no que diz respeito àqueles imigrantes que se destinaram ao interior paulista.

Refletir sobre os aspectos subjacentes a esse processo de construção (e também desconstrução) da italianidade, no contexto rural e urbano do interior paulista, é importante não só para o avanço do conhecimento do passado, mas também porque pode lançar luzes para pensar sobre a questão da identidade étnica dos latino-americanos, africanos, haitianos, sírios - os novos imigrantes, que estão se inserindo em áreas do interior paulista neste século XXI.

Nesse sentido, o novo livro de Oswaldo Truzzi - Italianidade no interior paulista. Percursos e descaminhos de uma identidade étnica (1880-1950) - é muito bem-vindo: entre vários outros fatores, a obra colabora para o entendimento dos processos que sustentam a construção da identidade étnica de estrangeiros em terras brasileiras.

Oswaldo Truzzi, professor da Universidade Federal de São Carlos (UFSCar) e engenheiro de formação, no decorrer de sua vida acadêmica passou a se dedicar à Sociologia e História Social das Migrações, o que vem fazendo assiduamente há três décadas. Hoje ele é reconhecido como um conceituado estudioso e conhecedor da imigração internacional no Brasil.

Em Italianidade no interior paulista, Truzzi discorre sobre como se configurou histórica e socialmente a identidade étnica dos italianos, no interior do estado de São Paulo, naquele momento importante do movimento migratório e da expansão da cafeicultura no oeste paulista. 0 estudo é feito a partir das pesquisas que o autor realizou ao longo dos anos e de uma leitura arguta e atenta de uma ampla bibliografia produzida no Brasil e no exterior, extraindo os elementos que vão fundamentar sua análise.

O livro é composto de um prefácio elaborado por Angelo Trento (do Istituto Orientale, Universidade de Nápoles), também importante estudioso da imigração italiana no Brasil, cinco capítulos, conclusão e muitas e significativas fotos que ilustram a vivência rural e urbana dos italianos no interior do estado de São Paulo.

No primeiro capítulo, ou item como prefere o autor - "À guisa de introdução teórica" -, ele argumenta que processos de afirmação de uma identidade e processos de assimilação marcaram a trajetória de italianos no interior paulista. Na análise desses processos, as referências teóricas são: o conceito de fronteira social - fronteira existente entre determinado grupo (no caso os italianos) e o restante da sociedade -, enfatizando que as variações da identidade étnica de um grupo ocorrem por meio de mudanças que acontecem em ambos os lados da fronteira no decorrer do tempo; e o conceito de assimilação reformulado, que não requer o desaparecimento da etnicidade, mas o reconhecimento de que as origens 
étnicas, de um modo geral, vão se tornando menos relevantes e que indivíduos de ambos os lados da fronteira tendem a se ver como similares em termos de algum outro fator (classe, por exemplo). Esse caminho pode variar muito ao longo do tempo, pois depende não só dos indivíduos ou grupos de indivíduos, mas também dos processos estruturais que oferecem, ou não, oportunidades e conteúdos identitários. Portanto, como já fizera em livro anterior, o autor reafirma que a identidade étnica deve ser entendida como "construção cultural historicamente determinada e iterativamente renegociada, por oscilações internas ao próprio grupo, quanto externas da sociedade mais ampla” (TRUZZI, 2008, p. 229).

A seguir, em "A profusão de italianos no interior paulista”, o autor resume os números e a evolução do movimento imigratório italiano, que atestam sua predominância no movimento migratório em direção ao Brasil e às áreas cafeeiras do interior paulista. Truzzi justifica que as particularidades do mundo rural e urbano do interior paulista merecem uma análise específica da italianidade.

No terceiro capítulo, "Uma identidade construída em São Paulo", é desenhado um panorama geral da política migratória brasileira - cujo objetivo era trazer trabalhadores estrangeiros em unidades familiares para a cafeicultura paulista. 0 autor traça o perfil dos imigrantes italianos, da maioria dos que se destacaram como colonos nas fazendas de café, camponeses pouco qualificados, originários principalmente do Vêneto e daqueles que, em menor volume, eram oriundos de outras regiões da Itália, que se inseriram em grande parte em outros nichos do mercado de trabalho como formadores de cafezal, mascates, pequenos artesãos e comerciantes.

O autor advoga que é temerário falar em uma italianidade trazida a São Paulo pelos imigrantes, tendo em vista a heterogeneidade dos contingentes italianos chegados ao Brasil e o fato de a unificação da Itália ter ocorrido há apenas duas décadas antes da entrada maciça desses imigrantes no território paulista. 0 correto, segundo ele, é "investigar os processos que presidiram a construção de uma italianità all'estero, isto é, aqui construí$\mathrm{da}$ - processos que se apresentaram àqueles que imigraram, em nosso caso específico, ao interior paulista" (TRUZZI, 2008, p. 36-37). Ou seja, um sentimento de pertencimento que se forma no país de adoção mesmo antes de ser experimentado por aqueles que permaneceram no local de origem.

Nessa direção, Truzzi argumenta que as mudanças na identidade foram impostas pelo próprio fenômeno imigratório e deveram-se à condição comum de imigrantes e ao contato com imigrantes de outras nacionalidades e com os nacionais, que conduziram ao reconhecimento paulatino deles como italianos, com uma identidade comum, à própria inserção como colonos nas fazendas de café (que levou os italianos a enfatizar sua distância e diferenciação em relação aos negros), à sua contribuição na formação de um mercado interno, à construção de uma ética de valorização do trabalho e ao início da formulação de uma ideologia de sucessos individuais.

No longo processo de formação de uma identidade italiana e de superação no país de adoção, o autor chama a atenção também para outros elementos que ajudaram parcialmente 
na formação dessa identidade: imprensa, escolas técnicas, o movimento étnico associativo e a constituição de uma elite italiana.

Nos dois capítulos seguintes, "No meio rural" e "No meio urbano", Truzzi destaca as vivências dos italianos e seus descendentes nestes dois mundos na construção de uma italianità all'estero.

"No meio rural", ele descreve a vida árdua que os italianos levavam nas fazendas de café e os aspectos que inibiam uma mobilização coletiva, formas de organização política e étnica: a rígida disciplina imposta pelo fazendeiro; o isolamento em que os colonos viviam no interior das fazendas; o pouco contato com o mundo exterior que restringia a sociabilidade; a dependência do armazém da fazenda e consequente endividamento com ela; a falta de escolas; e a ausência de vida cultural. 0 autor retoma Alvim (1986), ao salientar que a resistência dos colonos aos abusos dos fazendeiros e administradores das fazendas ocorria então com mudanças frequentes de fazenda em fazenda, para os núcleos urbanos ou retorno à terra natal.

Para além da vida na fazenda, Truzzi aponta outros fatores que contribuíram para debilitar a italianidade no meio rural: o declínio da imigração italiana no decorrer dos anos; o processo de diferenciação social progressiva entre os próprios italianos; e finalmente a depressão dos anos 1930, que levou muitos colonos para os centros urbanos. Diga-se de passagem, a geada de 1918 já havia dado início a esse processo nas áreas por ela atingidas. Mesmo o sonho da pequena propriedade, tão acalentado pelos italianos, sobretudo pelos vênetos, ao ser alcançado, não repercutiu no fortalecimento da identidade italiana no campo.

Truzzi dedica quase metade do livro ao último capítulo, “No meio urbano”. Com uma riqueza de exemplos, ele aborda em quatro itens a trajetória dos italianos na cidade na construção e des-etnização da italianidade.

0 primeiro item, “Processos de mobilidade”, começa por mostrar, como era de se esperar, que a cidade proporcionou aos imigrantes italianos e aos seus descendentes maior oportunidade de sociabilidade, associativismo, ascensão social e inserção em um mercado de trabalho diversificado, como empregadores ou empregados, principalmente no comércio e na indústria local. Na cidade, os italianos podiam contar ainda com escolas, assistência médica e religiosa. Nesse contexto, depois de alguns anos, vários imigrantes prosperaram individualmente e passaram a tecer relações com as oligarquias locais; "atravessaram a fronteira", demonstrando um processo de mobilidade social de italianos significativo no meio urbano.

Em seguida, em "O movimento associativo, divisões regionais e de classe", Truzzi salienta que a elite étnica, na sua maior parte oriunda do sul da Itália, se envolveu com a criação e desenvolvimento do associativismo, incentivada pela carência de instituições e ausência de uma política social que pudesse amparar os imigrantes na terra de adoção em termos econômicos, de saúde e educação. Porém, uma associação coletiva entre os imigrantes italianos não ocorreu tranquilamente: aos regionalismos que custaram a ser superados somaram-se no tempo as diferenças sociais e econômicas no interior da colônia 
italiana, a esperança inicial do retorno breve, a adaptação a um ambiente muito distinto da terra de origem, uma imprensa italiana pouco sólida, num mundo em que a maioria era analfabeta, e a ausência do Estado italiano na proteção aos seus emigrados.

A alteração a essa situação, analisada no item "Desdobramentos políticos na terra de origem”, veio com a ascensão do fascismo, que via com interesse a preservação dos laços com a coletividade italiana no exterior - como propagandista potencial dos interesses econômicos e políticos de uma nova Itália. $O$ fascismo incentivou uma militância muito mais forte entre os membros da elite imigrante do que em outros grupos. Nesse momento, no interior paulista as associações se fortaleceram e o fascismo consolidou uma italianidade que se manteve até o final da década de 1930. "Em alguma medida os fascistas lograram em promover, na mente dos emigrados italianos essa identidade entre regime e nação" (TRUZZI, 2008, p. 102). A decretação do Estado Novo, a entrada do Brasil na Segunda Guerra Mundial e a derrota da Itália anos depois deram o golpe final a esse processo.

O item final deste capítulo, “Desdobramentos políticos na terra de adoção”, demonstra que a política imigratória paulista indiretamente influenciou uma identidade étnica italiana ao "eleger e categorizar o italiano como agente privilegiado da implantação do trabalho livre na sociedade" (TRUZZI, 2008, p. 109). Os italianos eram vistos como bons trabalhadores, também contribuíam para o processo de embranquecimento da nação e não demandavam cargos políticos até então.

O contexto brasileiro e paulista dos anos 1930 abriu oportunidades de projeção social e econômica a muitos italianos, tais como a atuação em associações comerciais e industriais que passaram a ter uma inserção permanente na vida política local. 0 período do Estado Novo, ao impedir o cultivo da italianidade e de se fazer política por meio das associações étnicas, levou a elite italiana do interior a canalizar seus interesses, a partir de uma perspectiva profissional e mesmo classista. Na qualidade de membros de associações comerciais, sindicatos, associações hospitalares, rede escolar ou ocupando cargos públicos, os italianos e seus descendentes, a partir dos anos 1930, tiveram oportunidade de inserção política até então não pensada.

$\mathrm{Na}$ “Conclusão”, Truzzi resume os processos que levaram a uma italianidade all'estero e posteriormente à "des-etnização". 0 autor conclui, então, que com o passar dos anos a italianidade se converteu "a uma etnicidade vivenciada por indivíduos que podem 'se sentir étnicos' ocasionalmente em família, [...] em atividades de lazer e religiosas, mas que implica poucos compromissos na vida social do dia a dia.” (TRUZZI, 2008, p. 126), e que os muitos brasileiros nascidos em lares de famílias italianas acabaram se tornando definitivamente nacionais.

Esse livro de Truzzi representa sem dúvida uma contribuição importante aos estudos da imigração internacional e de modo especial para avançar sobre o entendimento da identidade étnica vivenciada no Brasil por imigrantes italianos. Sua leitura também abre caminhos para pensar, repensar ou aprofundar as questões que estão no bojo da construção ou des-construção da identidade étnica vivida por italianos em terras brasileiras 
- imigrantes oriundos de diferentes regiões, com características distintas, modos de vida diferentes, saídos da Itália em volume, composição e momentos diversos, aqui chegados subsidiados ou espontâneos, tomando destinos diversos e que se viram italianos all'estero. Há ainda muito a analisar em cada um desses aspectos, principalmente no que diz respeito às origens regionais e à trajetória dos mais e menos sucedidos na terra hospedeira.

A título de exemplo, um aspecto pontuado no livro, mas que merece ser aprofundado diz respeito às raízes regionais que poderiam estar embutidas nas muitas vivências dos imigrantes nesse outro lado do Atlântico.

Já se sabe que relações de produção, condições econômicas e forma de adensamento populacional explicam muitas das diferenças entre as populações do centro-norte e do sul da Itália. Na época analisada, no Vêneto e outras regiões do norte da Itália, por exemplo, metade ou mais da população vivia esparsamente. As famílias viviam na terra em que trabalhavam, enquanto no sul o local de residência era diferente do de trabalho.

$\mathrm{Na}$ Itália centro-setentrional, de meados dos anos 1800 até as primeiras décadas do século XX, predominaram domicílios e famílias complexas, embora a proletarização do campo tivesse aumentado o número de braccianti que viviam em famílias nucleares. Nessas regiões, seguiam normas patrilocais e as pessoas residiam longos períodos de sua vida em domicílios compostos por três gerações, unindo duas, três ou mesmo quatro unidades de famílias nucleares. No sul, uma alta proporção da população praticava residência neolocal após casamento e a maioria dos domicílios possuía estruturas simples (BARBAGLI, 1996). Tais características, por sua vez, influenciavam os papéis no interior da família, a distribuição de poder e a divisão das tarefas. Com que força então tais estruturas domiciliares e familiares dos imigrantes do norte e do sul da Itália se faziam presentes na construção da identidade étnica dos imigrantes no Brasil? Como as situações vividas no interior paulista ajudaram a preservar regras e valores da terra de origem aos quais estavam acostumados?

No caso dos vênetos, a pouca combatividade das populações rurais, a ausência de movimento de resistência camponesa do Vêneto e a emigração como forma de reação a um contexto de miséria e sofrimento, salientados por Franzina (2006), provavelmente somaram à realidade das fazendas para a pouca frequência de mobilizações coletivas nas áreas rurais paulistas, reagindo por meio das fugas ou mudanças de fazendas (ALVIM, 1984). Os imigrantes vênetos, ao que parece, vieram para ficar, sem a perspectiva da volta. "O insustentável presente de sofrimento e de misérias, e o desejo de uma renovada posse da terra, qualquer que fosse o preço, mesmo que além do Atlântico" (FRANZINA, 2006, p. 215), um projeto permanente e não temporário, inclusive porque entre eles predominou emigração familiar.

Os traços de mansidão e paciência, de não agressividade que marcaram a imagem dos vênetos teriam dificultado, para aqueles que migraram para as cidades e ascenderam social e economicamente, sua participação na vida política nas cidades do interior? Os espaços foram preenchidos pelos italianos do sul com maior experiência urbana, tidos como mais agressivos e que imigraram diretamente para os centros urbanos? É o que parece sugerir os exemplos citados por Truzzi. 
Enfim, para além de mostrar com muita desenvoltura a vivência dos italianos no Brasil e a complexidades de sua relação com a identidade italiana, o livro provoca no leitor outras questões, que precisam de aprofundamento, que desafiam e incentivam novas pesquisas.

\section{Referências}

ALVIM, Z. Brava gente: os italianos em São Paulo. 2. ed. São Paulo: Brasiliense, 1986.

BARBAGLI, M. Sotto lo stesso teto: Mutamenti dela famiglia in Italia dal XV al XX secolo. Bologna: Società Editrice II Molino, 1996.

FRANZINA, E. A grande emigração: o êxodo dos italianos do Vêneto para o Brasil. Campinas: Editora da Unicamp, 2006.

STERN, P. História das relações de gênero. São Paulo: Contexto, 2007.

TRUZZI, O. Patrícios - sírios e libaneses em São Paulo. 2. ed. São Paulo: Editora Unesp, 2008.

\section{Sobre a autora}

Maria Silvia Casagrande Beozzo Bassanezi é doutora em História, pesquisadora do Núcleo de Estudos de População “Elza Berquó” (Nepo), Universidade Estadual de Campinas (Unicamp).

\section{Endereço para correspondência}

Rua Dr. Shigeo Mori, 1294

13083-765 Campinas-SP, Brasil

Recebido para publicação em 13/06/2017

Aceito para publicação em 05/07/2017 